\title{
THE REPRESENTATIONS OF HINDLIMB DIGITS IN RAT DORSAL ROOT
}

\section{GANGLIA}

Alberto Prats-Galino ${ }^{1 *}$, Anna Puigdellívol-Sánchez ${ }^{1}$, Domingo Ruano-Gil ${ }^{1}$, Carl Molander $^{2,3}$.

1. Department of Morphological Sciences, Faculty of Medicine, University of Barcelona, 08036 Barcelona, Spain.

2. Department of Neuroscience, Karolinska Institutet, 17177 Stockholm, Sweden.

3. Department of Surgical Sciences, Section for Rehabilitation Medicine, Karolinska Hospital, 17176 Stockholm, Sweden.

Number of text pages (including tittle page, abstract, tables and figure legends): 27

Number of figures: 5 ( 2 of them in color)

Number of tables: 3

Abbreviated title: DRG representations of digits

Associate Editor: Jon H. Kaas, Forebrain Sensorimotor Systems and Plasticity, Department of Phisiology, Vanderbilt University 301, Wilson Hall, Nashville, TN 37240.

Key words: primary afferent neurones; toes innervation; three-dimensional reconstruction; somatotopic organisation; fluorescent dyes

Author for correspondence: Alberto Prats Galino

Department of Morphological Sciences

Faculty of Medicine, University of Barcelona

c/ Casanova, $n^{\circ} 143$

08036 Barcelona, Spain

E-mail: aprats@medicina.ub.es

Grant sponsor and grant number:

Secretaría de Estado de Universidades e Investigación (PM96-0059)

Fundació Marató TV3 (003-97)

Swedish Medical Research Council (11566) 


\begin{abstract}
The distribution in dorsal root ganglia of neurones which innervate the distal tips of the hindlimb digits in the rat were mapped after subcutaneous injections of the fluorescent tracers Fast Blue, Diamidino Yellow and Fluoro-Gold into different digits. Three-dimensional reconstruction was used to describe the intraganglionic distribution of neurones labelled from different digits. Labelled neurones were found mainly in the L3-L5 ganglia. The distribution in ganglia as well as the number of neurones labelled from each digit varied considerably between cases, but mean numbers of labelled neurones were similar for the different digits. Neurones in L3 tended to innervate medial digits and neurones in L5 tended to innervate lateral digits, but most neurones from any digit were found in L4. Although overlap was considerable, the threedimensional reconstruction revealed tendencies of neurones to be distributed in restricted territories within the dorsal root ganglia. This was especially clear in ganglion L5 where digit IV was found to be represented more rostrally than digit V. The results indicate that primary afferent neurones which innervate the hind limb digits are represented by a crude rostrocaudal somatotopic organisation both among and within lumbar dorsal root ganglia.
\end{abstract}




\section{INTRODUCTION}

The central projections of hindlimb sensory afferents have been found to be somatotopically arranged in the superficial laminae of the spinal cord of the rat (see Cervero and Connell, 1984; Molander and Grant, 1985; Swett and Woolf, 1985; Grant, 1993; Shortland and Woolf, 1993). The existence of a somatotopic organisation within dorsal root ganglia (DRGs) of the adult rat, however, has been a controversial matter (Ygge, 1984; Molander and Grant, 1985; Peyronnard et al., 1986, 1988; Wessels et al., 1990). Certain kinds of intraganglionic topography have been described in other animal species, such as adult frogs (Corner et al., 1978; Baker et. al., 1981) and cats (Kausz and Rethelyi, 1985). Furthermore, a somatotopic organisation has been reported in rats during development (Peyronnard et al., 1990; Wessels et al., 1990, 1994; Mirnics and Koerber, 1995) and, recently in adulthood, for the sciatic and femoral nerve afferents in the L4 dorsal root ganglion (DRG) (Puigdellívol et al., 1998a). In this study, we have re-examined the possibility of a somatotopical organisation of primary afferents in DRGs of the adult rat by studying the organisation of afferents from small, clearly separated distal targets. If such an organisation could be demonstrated it might be useful for studies of plastic changes after nerve injury. For this purpose we injected fluorescent tracers into the distal phalanges of the hind limb digits of normal adult rats, mapped the distributions and estimated the numbers of labelled neurones found in lumbar DRGs.

\section{MATERIALS AND METHODS}

Twenty-two adult female Sprague Dawley rats (200-350 g b.w.) were used in the present study. All the animals have been obtained from Harlan Interfauna Iberica S.A., maintained in the Animal Care Service, Faculty of Medicine, University of Barcelona, and treated in compliance with the ethical guidelines of this centre. Anaesthesia was initiated with ether and 
then continued with chloral hydrate $(300 \mathrm{mg} / \mathrm{kg})$ during surgical procedures and perfusion.

\section{Injections in digits}

The tips of the digits of the right hind limb foot were injected subcutaneously by means of a $10 \mu \mathrm{l}$ Hamilton Syringe attached to a 26 gauge needle for Fast Blue (FB) and Fluoro-Gold (FG), and to a 25S gauge needle for Diamidino Yellow (DY). An operating microscope was used for optimal control of the needle placement and to ensure tracer injection in the central plantar part of the tip of the digit. In a few cases there was a slight leakage from the injection opening. In those cases, the leaked tracer was aspirated with the syringe and reinjected with the aim to obtain equal injections between animals. Using combinations of 1-2 digits per animal, $0.5 \mu \mathrm{l}$ of either 5\% FB (Sigma), 5\% DY (EMS-Polyloy) or 2\% FG (Fluorochrome) were injected in each digit ( $\mathrm{n}=16$; Table 1). Furthermore, in some of the animals (Table 1), digits injected with FB or FG on day one were reinjected ten days later with $0.5 \mu 1$ or $1.5 \mu 1$ of $5 \%$ DY in an attempt to compare tracer efficacies. Only the results of the FB and FG injections will be shown here; the results of the second tracer will be presented elsewhere. In a second series of experiments (n=6), digit IV was injected with $1 \mu 1$ of $2 \%$ FG and digit V with $1 \mu 1$ of $5 \%$ FB (Table 1).

<Table 1 near here>

The results of this study are all based on unilateral experiments. However, as previous experiments have shown (unpublished) that labelling in contralateral DRGs does not occur after unilateral injection in digits, we injected also the contralateral side in some rats for the purpose of another study which will be presented elsewhere. 


\section{Fixation, sectioning, mounting and tissue examination}

Five to fifteen days after skin injection, the rats were re-anaesthetised and a thoracotomy was performed. After an intracardial injection of $1.000 \mathrm{IU}$ of heparin/kg b.w., the rats were perfused through the ascending aorta with $100 \mathrm{ml}$ of saline and then with $1.000 \mathrm{ml} 4 \%$ paraformaldehyde and $10 \%$ sucrose in phosphate buffer $(\mathrm{PB} ; \mathrm{pH} 7.4)$ for twenty minutes. The L3-L6 ganglia were removed, postfixed for 3 hours in the same perfusion solution, and then immersed in $15 \%$ sucrose in PB overnight. All ganglia were carefully oriented before embedding in Tissue-Tek ${ }^{\circledR}$ (Miles, Elkhart, USA) mounting medium so that the original orientation in the rat could be reconstructed. In this procedure, it was taken into account the macroscopic observation that the DRGs have a wider region caudally which projects in the medial direction and that the dorsal root exits laterally to the main mass of the ganglia.

The DRGs were cut on a cryostat in 16- $\mu$ m-thick longitudinal serial sections which were all thaw mounted on chrome-alum gelatinised (5\%) slides and then coverslipped with an antifading solution containing $1 \%$ paraphenylendiamine and $10 \%$ PBS in glycerol. Slides were examined within 2 hours after cutting in an Olympus Vanox fluorescent microscope, using ultraviolet light filters (DM 400 dichroic mirror and UG1 excitation filter, which gives a $365 \mathrm{~nm}$ excitation, $420 \mathrm{~nm}$ emission wavelength) and violet light filters (DM 455 dichroic mirror and BP 405 excitation filter, which gives a $405 \mathrm{~nm}$ excitation, $455 \mathrm{~nm}$ emission wavelength). The FB and DY labelling was examined with either violet or ultraviolet light filters whereas the FG labelling was examined with the ultraviolet filters.

The skin of the injected paws were peeled off and directly examined under epifluorescent illumination to determine the distribution of tracer near the injection site. 


\section{Neurone counts and correction factors}

Neuronal profiles with an identifiable nucleus were counted in every fifth consecutive section. The first section to be included in the counts was selected randomly among the first five sections. Preliminary estimates of the total number of labelled neuronal profiles per ganglion was calculated according to the formula $(c / s) * t s$ where $c$ is the number of counted neuronal profiles, $s$ is the number of sections in which profiles have been counted and $t s$ is the total number of sections. The estimated total numbers of labelled profiles from the digits were compared by an ANOVA-test.

A correction factor for split nuclei was calculated according to the formula $n(t / t+D-2 b)$, where $n$ is the estimated total number of cells before correction, $t$ is section thickness, $D$ the mean nuclear diameter and $b$ the height of a fragment too small to be detected (Floderus, 1944). In our material, we have considered $2 b$ as the diameter of the smallest measured neuronal nuclei. After measuring 60 neuronal profiles, the mean nuclear diameter was found to be $11.05 \pm 2.32$ $\mu \mathrm{m}$, and the smallest nuclear profile had a diameter of $7.24 \mu \mathrm{m}$. Thus, the correction factor of Floderus was calculated to 0.80 .

A second correction factor for split neurones was calculated by counting the number of labelled neurones in five DRGs obtained randomly from five different animals. Labelled neuronal profiles and ganglionic landmarks in photographs of all sections from these DRGs (mean 47.2 sections/ganglion) were copied by hand drawing to transparent papers which were superimposed to reveal labelled neuronal profiles which appear in more than one section. Each such neurone was counted only in the first section in which it appeared. The true number of labelled neuronal profiles so obtained was divided by the total number of labelled neuronal profiles observed (with or without a visible nucleus), giving a correction factor of 0.72 . 


\section{Three-dimensional reconstruction}

Three-dimensional reconstructions were made of each of DRGs L3-L5 to demonstrate the intraganglionic distribution of labelled neuronal profiles from a particular digit. The DRGs used for this purpose were first selected among those with a relatively small tendency of formation of cell islands in intraganglionic fascicles as this complicates the 3D reconstruction. From this selected sample, DRGs with neuronal counts as close as possible to the mean for each particular DRG and digit were used for 3D reconstruction (R79 for digit I and IV, R38 for digit II, R84 for digit III and R49 for digit V). In addition, DRG L5 was reconstructed in all the animals receiving simultaneous injections of digit IV and $V(n=6$, see Table 1).

Using an Olympus $\mathrm{BH} 2$ microscope with an attached drawing tube, every second of the consecutive serial sections was examined under a $4 \mathrm{x}$ objective at brightfield illumination. Its contours and main details: blood vessels, root fragments inside the ganglionic tissue, and section artefacts were outlined on a transparent paper at a final magnification of $44 x$. Using those details as landmarks, the sections were re-examined with violet or ultraviolet light and the positions of labelled neuronal profiles were plotted inside the previously drawn profiles of the sections. The possible reduction of the detected number of labelled neuronal profiles that might result from fading in this process could be discarded by the finding that the numbers of labelled neuronal profiles were the same before and after the making of the drawings.

The computer analysis consists of three steps: (i) digitisation of positions of labelled cells and ganglionic tissue contours using a digitising tablet (Digicad) connected to an image analysis system (IMCO 10, Kontron, Munich, Germany), (ii) 3-D surface reconstruction from aligned serial sections by triangularisation using a specially developed software (Prats-Galino et al., 1988), and finally (iii) generation of a shaded 3D model from the resulting triangular facets using 3D Studio Max 1.2 software (Kinetix, Autodesk,Inc.). Original data files were transformed 
to VRML format and then converted by the Crossroad File Format Converter into Autocad DXF format which could be imported into 3D Studio Max. The opacity of the ganglionic surface was diminished up to a $30 \%$ to allow visualisation of the spheres representing neurones inside. The model was reconstructed in dorsal views and has a final resolution in the Z-plane of $30 \mu \mathrm{m}$ and about 90 to $100 \mu \mathrm{m}$ in the $\mathrm{X}$ and Y planes. The graphic output TIF format files, with dorsal views of the ganglia, were finally imported and mounted in a Powerpoint 97 document (Microsoft) and printed using a Kodak Digital Science 8650 PS Colour Printer.

To visualise the neurones projecting to the different digits in a single DRG model representing each segmental level, the mean widths and lengths of the reconstructed DRGs at each level were calculated. These values were used to calculate the size of each ganglion model and to recalculate the co-ordinates of the neuronal positions inside to mach the size of the models. Finally, the re-sized co-ordinates of each neuronal population were merged with the corresponding ganglion model and rendered with 3D Studio Max to generate the final integrated image.

\section{RESULTS}

\section{Specificity of injection site}

Examination of the skin and subcutaneous parts of the paws showed that the distribution of the injected tracers was always restricted to the injected digits, with the main distribution in their most distal parts.

\section{Character of the labelling}

The FB and DY labelling was visible under both violet and ultraviolet light. Neuronal profiles identified as FB labelled showed an intense blue fluorescence in the cytoplasm (Fig. 1) 
and sometimes in the nucleus. Neuronal profiles identified as DY labelled showed an intense yellow fluorescence in the nucleus, and less staining in the cytoplasm (Fig. 1). Finally, neuronal profiles identified as FG labelled showed a reddish labelling restricted to the cytoplasm with ultraviolet light filters (Fig. 1) and was comparatively less well visualised under the violet filter. Nucleoli were visible as a shadow in DY labelled nuclei and sometimes in FB labelled nuclei.

<Fig.1 near here>

Vascular spread of the tracer was suspected in cases where all neuronal profiles showed a very faint FB or FG labelling. The difference in labelling intensity between these cells and those labelled from axonal transport was evident and was not considered to cause any problem regarding identification. Diamidino Yellow did not show such vascular spread in any case.

Qualitative observations showed that there was no apparent difference in FB labelling intensity between animals sacrificed at 5 days and at 15 days after tracer injection (data not shown).

No differences were found between the counts of neuronal labelled profiles made before and after the drawing of the sections (data not shown).

\section{Representations of digits in the DRGs}

Observations in five rats showed that less than five labelled neuronal profiles were seen in the L2 and L6 DRGs after injections in digits I and V, respectively. These ganglia were therefore excluded from further analysis in this investigation. Furthermore, as no labelled neuronal profiles were found in the L3 DRG after injection in digits IV and V, this DRG was examined in detail only after injections in digits I, II, and III. 
The total number of neuronal profiles labelled from a particular digit varied considerably between animals, ranging from 154.3 to 780.2 in the most extreme (digit III). However, mean numbers of neuronal profiles per digit were similar (range 410.1 to 472.4 , Table 2 ) and no significant difference was found when those means were compared $(\mathrm{p}=0.9756)$.

Considerable variation in the number of neuronal profiles in a DRG after injection in a particular digit was found when different animals were compared (Table 2). Furthermore, the mean numbers of labelled neuronal profiles after injection in the different digits was different for each DRG level (Table 3). In general, labelled neuronal profiles in DRG L3 were found mainly after injection in digits I and II, whereas labelled neuronal profiles in DRG L5 were found mainly after injection in digits IV and V. Digits II-IV, especially digit III, tended to be more represented in DRG L4 and less in L3 and L5 (Table 3 and Fig. 2).

$<$ Table 2,3 and Fig. 2,3 near here>

\section{Intraganglionic representation of digits}

Examination of the three-dimensional representations of separate digits in the lumbar DRGs revealed a sparse distribution of labelled neuronal profiles with no or little tendency to form clusters (Fig. 3). Some DRG regions appeared to be unlabelled by particular digits. Thus, in the three-dimensional reconstructions of separate cases, digit I tended to be distributed mainly caudally in L3 and rostrally in L5, digit II was unrepresented in the rostral parts of L4, digit III and IV appeared mainly rostrally in L5, and digit V appeared mainly centrally in L4 and L5 (Fig. 3). However, when observing the location of neuronal profiles belonging to the different digits together in single ganglion composites (Fig. 4) a substantial overlap was found for the different populations, especially in L4. Viewed this way, the only relative arrangement found was that 
digit IV appeared to be represented more rostrally than digit V in L5. This particular arrangement was found to be consistent in 4 out of 6 animals subjected to an extended analysis of the representations of digits 4 and 5 in L5. Thus, separated distributions were seen in R136, 138, 139 and 162, but not in R137 and R140 where both populations seemed to be intermixed (Fig. 5).

<Fig. 4 and 5 near here>

\section{DISCUSSION}

\section{Technical considerations}

In order to facilitate the mapping of the topographical relation between neurones labelled from different digits, we injected several digits with different tracers in the same animal.

Previous studies in our laboratory have shown that the three tracers used seem to label the same populations of afferents with similar efficiency (Puigdellívol et al., 1998b). However, to further avoid the possibility of such bias, we also varied the tracer used for the same digit between cases.

For practical reasons we could not use the optical disector method (Sterio, 1984; Pover and Coggeshall, 1991) to avoid overestimate in cell counts due to split cells. First, the number of labelled neurones in each section was small and varied considerably. Second, we did not have access to the technology needed to perform the disector method using ultraviolet light. Third, the sections were not oriented randomly. Instead, we used two different methods of estimating cell numbers; correction factors for split nuclei according to the classical but somewhat less reliable Floderus method (Floderus, 1944), and analysis of the real number of labelled neurones in a sample (Coggeshall and Chung, 1984; Coggeshall et al., 1990; Novikova et al., 1997) by 
superimposing transparencies from prints of adjacent sections. These methods do not, however, allow an ideal estimate of the true number of neurones. By using the diameter of the smallest nucleus as $2 b$ in the denominator of the Floderus formula instead of $0.5 \mu \mathrm{m}$ (see Köningsmark, 1970), our factor should be a slight overestimate of the true correction factor. However, the correction factor obtained by superimposing transparencies from adjacent prints is certainly an underestimate of the true factor, as is based on the counting of whole cells rather than nuclei, which was used in the general counting. Whole cell counting was used, since it was not possible to see all nuclei accurately in the photographs that were used for the purpose of calculating this factor. As the correction factors obtained with these two methods were found to be close and because one of them is likely to be an underestimate and the other an overestimate, we find it conceivable that the true factor lies between 0.72 and 0.80 .

A considerable variation in the number of labelled neurones from a single digit was found between animals. This is most likely due to technical factors such as difficulties to perform identical injection in different animals, leakage of tracer out of the injected digit (although special measures were taken to reduce this factor, see Methods), and variable subcutaneous spread inside the digit. It may also be due to true inter-animal differences in the number of cells in individual DRGs (Ygge et al., 1981; Avendaño and Lagares, 1996).

We used computerised three-dimensional reconstruction to study the intraganglionic organisation of afferents from the different digits. Three-dimensional reconstruction of neuronal organisation has previously been used to show the DRG topography of primary muscle afferent neurones (Peyronnard et al., 1990). Similar or related techniques have been used to demonstrate the outlines of certain CNS nuclei (Prats-Galino et al., 1988; McRitchie and Törk, 1993; Bayer et al., 1991, 1994), the topography of neuronal cell populations in the CNS (Filiano et al., 1990; Huang et al., 1993; Ishihara et al., 1995), and boundaries of cortical areas (Funnell et al., 1990; 
Bayer et al., 1991). To us, it is clear that the use of three-dimensional reconstruction in this study facilitated the search for a topographical organisation in the DRG as compared to the classical way of examining serial sections. This might be the reason why we were able to demonstrate a gross somatotopical organisation in contrast to previous investigators.

\section{Organisation of digit projecting neurones in the DRG}

A somatotopic organisation of the central projections of primary afferents which innervate the hind limb digits in the rat has previously been demonstrated after skin injections of wheatgerm agglutinin conjugated to horseradish peroxidase (Molander and Grant, 1985) and after intracellular injections of horseradish peroxidase into physiologically characterised afferents whose peripheral receptive field had been identified (Shortland and Woolf, 1993). Despite a clear somatotopic organisation of primary afferent projections from the digits in the spinal cord, a corresponding organisation in the DRG has not been demonstrated (cf. Molander and Grant, 1985). There are several indications that there might be a somatotopical organisation, however. Peyronnard et al. $(1986,1990)$ reported that afferent neurones from different hindlimb muscles tend to form separate clusters in lumbar DRGs, although the inconsistent localisation of the clusters raised doubts as to whether they were truly somatotopic or not. Furthermore, at the trigeminal level, where the targets are closer to the ganglion, a clear arrangement of primary afferents has repetitively been described (see Aker and Reith, 1981; Jacquin et al., 1983; Nishimori et al., 1986; Keller et al., 1991; Anton and Peppel 1991; Kobayashi and Matsamura, 1996).

The results of this study show a considerable overlap in the DRG representations of the different digits, both with regard to the DRGs in which the digits are represented and with regard to the intraganglionic representations of digits. There is, however, a clear tendency of a 
rostrocaudal organisation such that medial digits are represented more rostrally than lateral digits in the DRGs. A similar organisation has previously been observed in fetal (Wessels et al., 1990) and neonatal rats (Wessels and Marani, 1993) after labelling of hindlimb nerve afferents. This finding is not unexpected considering the embryonic development in which the medial side of the foot is located rostral to the lateral side, and is also reflected by a corresponding rostrocaudal organisation in the central projections in the spinal cord (Molander and Grant, 1985; Shortland and Woolf, 1993). In the DRGs of adult rats, however, such an organisation has been reported to be hard to demonstrate (Wessels et al., 1994). We also demonstrate a clear tendency for separate representations of digits IV and V within the L5 DRG that follows the rostrocaudal order described above. This finding was relatively consistent despite the great variation in the number of labelled neurones from a single digit found between animals (see fig 5). Although a similar organisation was observed also for other digits in the different DRGs, further work is needed to demonstrate its consistency, especially in the L4 DRG where most digits were represented to some degree. This does not rule out that there might be a somatotopic organisation also in this DRG, it is just harder to see when all digits are considered. Interestingly, we recently showed that the femoral nerve and the sciatic nerve, which is the main nerve that innervates the hindlimb digits, have separate but slightly overlapping representations in the L4 DRG (Puigdellívol et al., 1998a). Even though a clear tendency of a somatotopic organisation within and between the DRGs of neuronal cell bodies subserving the different digits seems to be present, it is much less pronounced than that of the central projections of those neurones. It is possible that this phenomenon arises from a random clustering of the neurones as the neural crest is divided by the emerging somites. Furthermore, in contrast to the spinal cord dorsal horn, the interrelations of the afferent cell bodies in the DRGs may be of little functional importance as they seem to lack synaptic contacts, at least under normal conditions (McLachlan et al., 1993). 
A detailed description of the topographical organisation of the representations of the digits in DRGs is of interest as it may be a primary step to form an experimental model to study the topographical accuracy of distal nerve regeneration after nerve injury. The distal parts of the digits would offer a possible tool for such investigations. In previous studies, the technique of retrograde tracing has been used to study motor reinnervation after facial nerve injury (Aldskogius and Thomander, 1986) and of motor reinnervation after sciatic nerve injuries (Aldskogius et al., 1987). A reorganisation of the topographical organisation of retrogradely labelled neuronal cell bodies following the nerve injury indicated inaccurate peripheral regeneration in those studies. Although the results of the present study, showing a considerable overlap of the representations of adjacent digits in the DRG as well as inter-animal variation, indicates that such studies would be difficult to perform, it might be possible if the adjacent digits IV and V are used, or perhaps if non-adjacent digits are used.

\section{ACKNOWLEDGEMENTS}

We thank Dolors Fuster and Nieves Cayuela for technical assistance and Carol Mendoza for collaborating in the digitalisation of some of the ganglionic and neuronal profiles. This work has been supported by grants from the Secretaría de Estado de Universidades e Investigación, Programa Sectorial de Promoción General del Conocimiento (PM96-0059), the Fundació Marató TV3 (003/97) and the Swedish Medical Research Council, project No. 11566. We thank Dr Peter Shortland, Dr Håkan Aldskogius and Dr Brun Ulfhake for valuable comments.

\section{LITERATURE CITED}

Aker, D.F. and E.J. Reith (1981) Innervation of rat molar teeth: I. Distribution of neuronal cell bodies in the trigeminal ganglion from a mandibular molar tooth. Anat. Rec. 
201:23-29.

Anton, F. and P. Peppel (1991) Central projections of trigeminal primary afferents innervating the nasal mucosa: a horseradish peroxidase study in the rat. Neuroscience. 41:617628.

Aldskogius, A. and L. Thomander (1986) Selective reinnervation of somatotopically appropriate muscles after facial nerve transection and regeneration in the neonatal rat. Brain Res. $375: 126-134$.

Aldskogius, H., C. Molander, J. Persson, and L.Thomander (1987) Specific and nonspecific regeneration of motor axons after sciatic nerve injury and repair in the rat. J. Neurol. Sci. 80:249-257.

Avendaño, C. and A. Lagares (1996) Stereological analysis of the numerical distribution of neurones in dorsal root ganglia C4-T2 in adult macaque monkeys. Somatosens. Motor Res. 13:59-66.

Baker, R.E., K. Matesz, M.A. Corner, and G. Szekely (1981) Peripheral reinnervation patterns and dorsal root ganglion topography in skin-grafted frogs: a behavioural and histological examination. Dev. Neurosci. 4:134-141.

Bayer, S.A., J. Altman, R.J. Russo, X.F. Dai, and J.A. Simmons (1991) Cell migration in the rat embryonic neocortex. J. Comp. Neurol. 307: 499-516.

Bayer, S.A., L.C. Triarhou, J.D. Thomas, and B. Ghetti (1994) Correlated quantitative studies of the neostriatum, nucleus accumbens, substantia nigra, and ventral tegmental area in normal and weaver mutant mice. J. Neurosci. 14: 6901-6910.

Cervero, F. and L.A. Connell (1984) Fine afferent fibers from viscera do not terminate in the substantia gelatinosa of the thoracic spinal cord. Brain Res. 294:370-374.

Coggeshall, R.E. and K. Chung (1984) The determination of an empirical correction 
factor to deal with the problem of nucleolar splitting in neuronal counts. J. Neuroci. Meth. 10:149-155.

Coggeshall, R.E., R. La Forte, and D.M. Klein (1990) Calibration of methods for determining numbers of dorsal root ganglion cells. J. Neurosci. Methods. 35:187-194.

Corner, M.A., W.A.Veltman, R.E. Baker, and J. Van de Nes (1978) Topography of cutaneous spinal ganglion cells in the frog (Rana esculenta). Brain Res. 156:151-156.

Filiano, J.J., J.C. Choi, and H.C. Kinney (1990) Candidate cell populations for respiratory chemosensitive fields in the human infant medulla. J. Comp. Neurol. 293:448-465.

Floderus, S. (1944) Untersuchungen über den Bau der Menschlichen Hypophyse mit besonderer Berucksichtigung der qualitativen mikromorphologischen Verhältnisse. Acta Pathol. Microbiol. Scand. 53:1-276.

Funnell, W.R.J., D. Maysinger, and A.C. Cuello (1990) Three-dimensional reconstruction and quantitative evaluation of devascularizing cortical lesions in the rat. J. Neurosci. Methods 35:147-156.

Grant, G. (1993) Projection of primary sensory neurones studied by transganglionic methods: somatotopy and target-related organisation. Brain Res. Bull. 30:199-208.

Huang, X.F., I. Törk, and G. Paxinos (1993) Dorsal motor nucleus of the vagus nerve: a cyto- and chemoarchitectonic study in the human. J. Comp. Neurol. 330:150-182 .

Ishihara, A., R.R. Roy, and R.V. Edgerton (1995) Succinate dehydrogenase activity and soma size of motoneurons innervating different portions of the rat tibialis anterior. Neuroscience 68:813-822.

Jacquin, M.F., K. Semba, M.D. Egger, and R.W. Rhoades (1983) Organization of HRPlabeled trigeminal mandibular primary afferent neurons in the rat. J.Comp.Neurol. 215:397-420. 
Kausz, M. and M. Rethelyi (1985) Lamellar arrangement of neuronal somata in the dorsal root ganglion of the cat. Somatosens. Res. 2:193-204.

Keller, J.T., H.C. Bubel, A.H. Wander, and B.E. Tierney (1991) Somatotopic distribution of corneal afferent neurons in the guinea pig trigeminal ganglion. Neurosci. Lett. $121: 247-250$.

Kobayashi, Y. and G. Matsamura (1996) Central projections of primary afferent fibers from the rat trigeminal nerve labeled with isolectin B4-HRP. Neurosci. Lett. 217:89-92.

Königsmark, B.W. (1970) Methods for the counting of neurones. In W.J.H. Nauta and S.O.E. Ebbeson (eds): Contemporary Research Methods in Neuroanatomy. Berlin: SpringerVerlag, pp. 315-338.

McLachlan, E.M., W. Jänig, M. Devor, and M. Michaelis (1993) Peripheral nerve injury triggers noradrenergic sprouting within dorsal root ganglia. Nature 363:543-546.

McRitchie, D.A. and I. Törk (1993) The internal organisation of the human solitary nucleus. Brain Res. Bull. 31:171-193.

Mirnics, K. and H.R. Koerber (1995) Prenatal development of rat primary afferent fibers: I. Peripheral projections. J. Comp. Neurol. 355:589-600.

Molander, C. and G. Grant (1985) Cutaneous projections from the rat hindlimb foot to the substantia gelatinosa of the spinal cord studied by transganglionic transport of WGA-HRP conjugate. J. Comp. Neurol. 237:476-484.

Nishimori, T., M. Sera, S. Suemune, A.Yoshida, K. Tsuru, Y. Tsuiki, T. Akisaka, T. Okamoto, Y. Dateoka, and Y. Shigenaga (1986) The distribution of muscle primary afferents from the masseter nerve to the trigeminal nuclei. Brain Res. 372:375-381. 
Novikova, L., L. Novikov, and O. Kellerth (1997) Persistent neuronal labelling by retrograde fluorescent tracers: a comparison between Fast Blue, Fluoro-Gold and various dextran amines. J. Neurosci. Methods. 74:9-15.

Peyronnard, J.M., L.F. Charron, J. Lavoie, and J.P. Messier (1986) Motor, sympathetic and sensory innervation of rat skeletal muscles. Brain Res. 373:288-302.

Peyronnard, J.M., L.F. Charron, J. Lavoie, J.P. Messier, and M. Dubreil (1988) Carbonic anhydrase and horseradish peroxidase: double labelling of rat dorsal root ganglion neurones innervating motor and sensory peripheral nerves. Anat. Embryol. 177:353-359.

Peyronnard, J.M., J.P. Messier, M. Dubreuil, L. Charron, and F. Lebel (1990) Threedimensional computer-aided analysis of the intraganglionic topography of primary muscle afferent neurones in the rat. Anat. Rec. 227:405-417.

Pover, C.M. and R.E. Coggeshall (1991) Verification of the disector method for counting neurones, with comments on the empirical method, Anat. Rec. 231:573-578.

Prats-Galino, A., C. Costa-Llobet, J. Arroyo-Guijarro, and D. Ruano-Gil (1988) The facial motor nucleus of the dog. I. Cytoarchitectonic subdivisions and cytology. Acta Anat. $132: 276-279$.

Puigdellívol-Sánchez, A., A. Prats-Galino, D. Ruano-Gil, and C. Molander (1998a) Sciatic and femoral nerve sensory neurones occupy different regions of the L4 dorsal root ganglion in the adult rat. Neurosci. Lett. 251:169-72.

Puigdellívol-Sánchez, A., A. Prats-Galino, D. Ruano-Gil, and C. Molander (1998b) Efficacy of the fluorescent dyes Fast Blue, Fluoro-Gold, and Diamidino Yellow for retrograde tracing to dorsal root ganglia after subcutaneous injection. J. Neurosci. Methods. 86:7-16. 
Shortland, P. and C.J. Woolf (1993) Morphology and somatotopy of the central arborizations of rapidly adapting glabrous skin afferents in the rat lumbar spinal cord. J. Comp. Neurol. 329:491-511.

Sterio, D.C. (1984) The unbiased estimation of number and sizes of arbitrary particles using the dissector. J. Microsc. 134:127-136.

Swett, J.E. and C.J. Woolf (1985) The somatotopic organisation of primary afferent terminals in the superficial laminae of the dorsal horn of the rat spinal cord. J. Comp. Neurol. 231:66-77.

Wessels, W.J.T. and E. Marani (1993) A rostrocaudal somatotopic organisation in the brachial dorsal root ganglia of neonatal rats. Clin. Neurol. Neurosurg. 95:S3-S11.

Wessels, W.J.T., H.K.P. Feirabend, and E. Marani (1990) Evidence for a rostrocaudal organisation in dorsal root ganglia during development as demonstrated by intra-uterine WGAHRP injections into the hindlimb of rat fetuses. Dev. Brain Res. 54:273-281.

Wessels, W.J.T., H.K.P. Feirabend, and E. Marani (1994) The rostrocaudal organisation in the dorsal root ganglia of the rat: a consequence of plexus formation? Anat. Embryol. 190:111.

Ygge, J. (1984) On the organisation of the thoracic spinal ganglion and nerve in the rat, Exp. Brain Res. 55:395-401.

Ygge, J., H. Aldskogius, and G. Grant (1981) Asymmetries and symmetries in the number of thoracic dorsal root ganglion cells. J. Comp. Neurol. 202:365-372. 
TABLE 1. Different combinations of tracer injection. All Injections were made 5 days before perfusion except those marked by an asterix which were made 15 days before perfusion. Note that some animals were injected twice in the same digit on two different occasions (see text).

\begin{tabular}{|c|c|c|c|c|c|}
\hline Case & Digit I & Digit II & Digit III & Digit IV & Digit V \\
\hline R25 & & $0.5 \mu \mathrm{FB}$ & $0.5 \mu \mathrm{FG}$ & & \\
\hline R26 & & $0.5 \mu \mathrm{FG}$ & $0.5 \mu \mathrm{l} \mathrm{FB}$ & & \\
\hline $\mathrm{R} 28$ & & & $0.5 \mu \mathrm{FG}$ & & \\
\hline R29 & & $0.5 \mu \mathrm{FB}$ & & & \\
\hline R38 & & $0.5 \mu \mathrm{FB}$ & & & \\
\hline R39 & & & $0.5 \mu \mathrm{FB}$ & & \\
\hline $\mathrm{R} 44$ & & & & $0.5 \mu \mathrm{FG}$ & $0.5 \mu \mathrm{FB}$ \\
\hline $\mathrm{R} 45$ & & $0.5 \mu \mathrm{FB}$ & & $0.5 \mu \mathrm{FG}$ & \\
\hline $\mathrm{R} 48$ & $0.5 \mu \mathrm{D} \mathrm{DY}$ & & & & $0.5 \mu \mathrm{lFG}$ \\
\hline R49 & $0.5 \mu \mathrm{lFG}$ & & & & $0.5 \mu \mathrm{l} \mathrm{DY}$ \\
\hline \multirow[t]{2}{*}{$\mathrm{R} 50$} & & & & & $0.5 \mu \mathrm{FB}{ }^{*}$ \\
\hline & & & & & $1.5 \mu \mathrm{D} \mathrm{DY}$ \\
\hline \multirow[t]{2}{*}{ R51 } & & & & & $0.5 \mu \mathrm{lFB}$ \\
\hline & & & & & $1.5 \mu \mathrm{lDY}$ \\
\hline \multirow[t]{2}{*}{ R77 } & $0.5 \mu \mathrm{l} \mathrm{FG}$ & & & $0.5 \mu 1 \mathrm{FB}^{*}$ & \\
\hline & & & & $0.5 \mu \mathrm{l} \mathrm{DY}$ & \\
\hline \multirow[t]{2}{*}{ R78 } & $0.5 \mu l \mathrm{FG}$ & & & $0.5 \mu 1 \mathrm{FB}^{*}$ & \\
\hline & & & & $0.5 \mu 1 \mathrm{DY}$ & \\
\hline \multirow[t]{2}{*}{ R79 } & $0.5 \mu \mathrm{FG}$ & & & $0.5 \mu 1 \mathrm{FB}^{*}$ & \\
\hline & & & & $0.5 \mu 1 \mathrm{DY}$ & \\
\hline R84 & & & $0.5 \mu \mathrm{FB}$ & & \\
\hline R136 & & & & $1 \mu \mathrm{FG}$ & $1 \mu \mathrm{FB}$ \\
\hline R137 & & & & $1 \mu \mathrm{FG}$ & $1 \mu \mathrm{FB}$ \\
\hline R138 & & & & $1 \mu \mathrm{FG}$ & $1 \mu \mathrm{FB}$ \\
\hline R139 & & & & $1 \mu \mathrm{lFG}$ & $1 \mu \mathrm{lFB}$ \\
\hline R140 & & & & $1 \mu \mathrm{FB}$ & $1 \mu \mathrm{FG}$ \\
\hline
\end{tabular}


TABLE 2. Numbers of neurones labelled from each digit. Estimates of the total number of neuronal profiles in the L3-L5 DRGs labelled from each digit using the $(\mathrm{c} / \mathrm{s}) *$ ts formula (see text). The tracer used in each case is indicated. Numbers have not been corrected for split nuclei (see text).

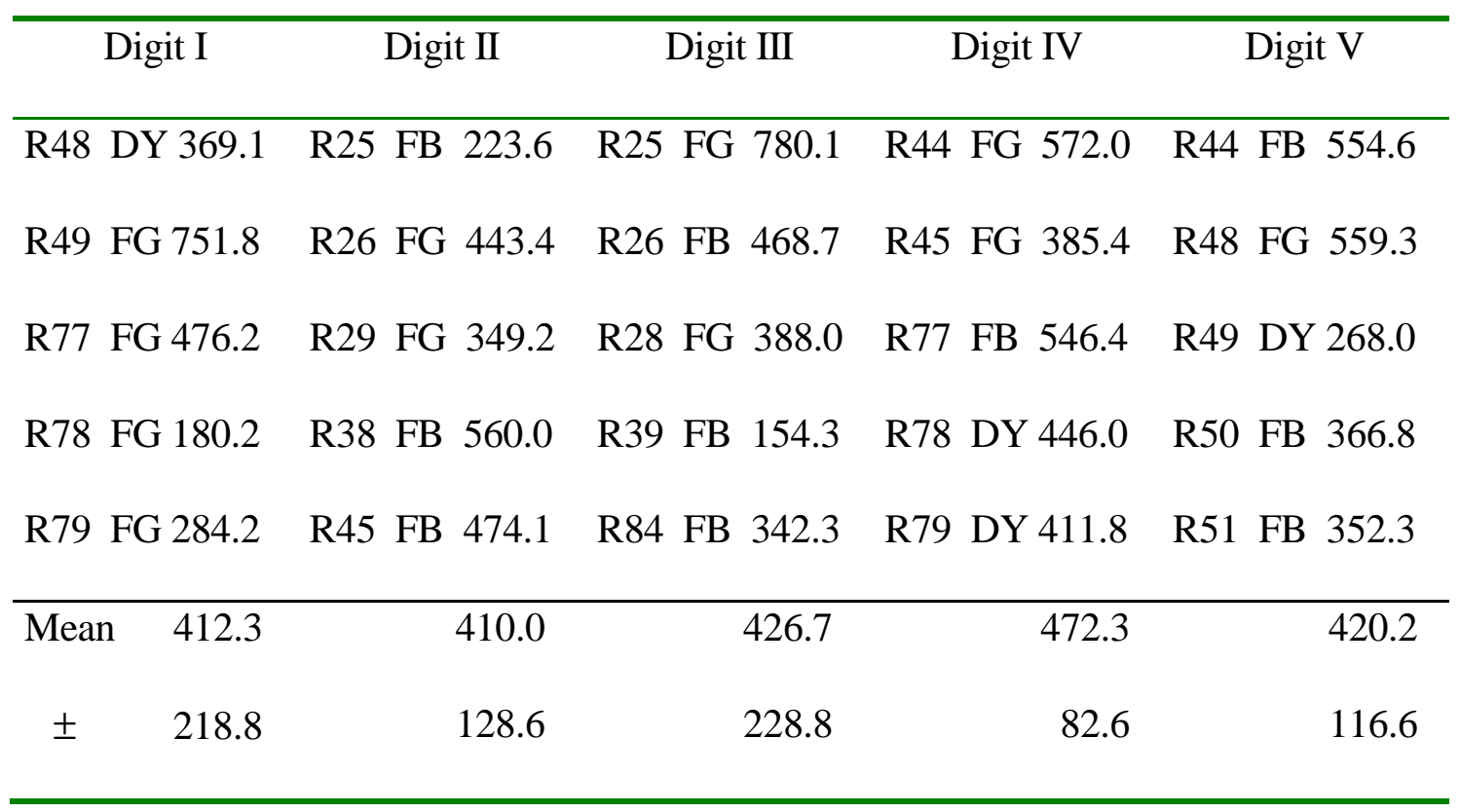


TABLE 3. Numbers of neurones in the different DRGs, labelled from different digits.

Estimates of labelled neuronal profiles in DRGs L3-L5 after injection in digits I-V. Numbers have not been corrected for split nuclei (see text).

\begin{tabular}{|c|c|c|c|c|c|c|c|c|c|c|}
\hline DRG & Case & Digit I & Case & Digit II & Case & Digit III & Case & Digit IV & Case & Digit V \\
\hline \multirow{5}{*}{ L3 } & R 48 & 36.0 & R25 & 4.0 & $\mathrm{R} 25$ & 0.0 & $\mathrm{R} 44$ & 0.0 & $\mathrm{R} 44$ & 0.0 \\
\hline & R 49 & 264.5 & R26 & 84.0 & R26 & 4.0 & $\mathrm{R} 45$ & 0.0 & $\mathrm{R} 48$ & 0.0 \\
\hline & R 77 & 85.8 & R29 & 24.5 & $\mathrm{R} 28$ & 20.0 & R77 & 0.0 & $\mathrm{R} 49$ & 0.0 \\
\hline & R 78 & 16.5 & R38 & 84.0 & R39 & 0.0 & R78 & 0.0 & $\mathrm{R} 50$ & 0.0 \\
\hline & R 79 & 42.4 & $\mathrm{R} 45$ & 64.9 & $\mathrm{R} 84$ & 0.0 & R79 & 0.0 & $\mathrm{R} 51$ & 0.0 \\
\hline Mean & & 89.0 & & 52.2 & & 4.8 & & 0.0 & & 0.0 \\
\hline \multirow[t]{3}{*}{ \pm} & & 101.3 & & 36.3 & & 8.6 & & 0.0 & & 0.0 \\
\hline & R 48 & 220.4 & R25 & 200.7 & R25 & 656.5 & R44 & 447.2 & R44 & 203.6 \\
\hline & R 49 & 392.8 & R26 & 315.0 & R26 & 350.0 & $\mathrm{R} 45$ & 327.6 & $\mathrm{R} 48$ & 91.2 \\
\hline \multirow[t]{3}{*}{$\mathrm{L} 4$} & R 77 & 390.4 & R29 & 270.1 & R28 & 340.0 & R77 & 383.4 & R49 & 68.5 \\
\hline & R 78 & 156.0 & R38 & 392.0 & R39 & 124.0 & R78 & 260.0 & $\mathrm{R} 50$ & 96.7 \\
\hline & R 79 & 226.8 & $\mathrm{R} 45$ & 399.0 & R84 & 292.3 & R79 & 177.8 & R51 & 273.1 \\
\hline Mean & & 277.3 & & 315.3 & & 352.5 & & 319.2 & & 146.6 \\
\hline \multirow[t]{3}{*}{ \pm} & & 108.0 & & 83.7 & & 192.6 & & 104.9 & & 87.9 \\
\hline & R 48 & 112.7 & R25 & 18.8 & R25 & 123.6 & R44 & 124.8 & R44 & 351.0 \\
\hline & R 49 & 94.5 & R26 & 44.4 & R26 & 114.7 & $\mathrm{R} 45$ & 57.8 & $\mathrm{R} 48$ & 468.0 \\
\hline \multirow[t]{3}{*}{ L5 } & R 77 & 0.0 & R29 & 54.6 & $\mathrm{R} 28$ & 28.0 & R77 & 163.0 & R49 & 199.5 \\
\hline & R 78 & 7.7 & R38 & 84.0 & R39 & 30.3 & R78 & 186.0 & $\mathrm{R} 50$ & 270.1 \\
\hline & R 79 & 15.0 & $\mathrm{R} 45$ & 10.2 & R84 & 50.0 & R79 & 234.0 & $\mathrm{R} 51$ & 79.2 \\
\hline Mean & & 46.0 & & 42.4 & & 69.3 & & 153.1 & & 273.5 \\
\hline \pm & & 53.3 & & 29.4 & & 46.3 & & 66.3 & & 147.5 \\
\hline
\end{tabular}




\section{FIGURE LEGENDS.}

Figure 1. Photograph of labelled neuronal profiles in dorsal root ganglion. Diamidino Yellow labelled neuronal profiles (DY) shows a clearly labelled yellow nucleus and occasionally cytoplasmatic labelling. Fast Blue (FB) and Fluoro-gold (FG) labelled neuronal profiles show a blue or reddish labelling located mainly in the cytoplasm. Some labelling occur in surrounding glia, indicating spread from the retrogradely labelled neurones. Scale bar: $50 \mu \mathrm{m}$.

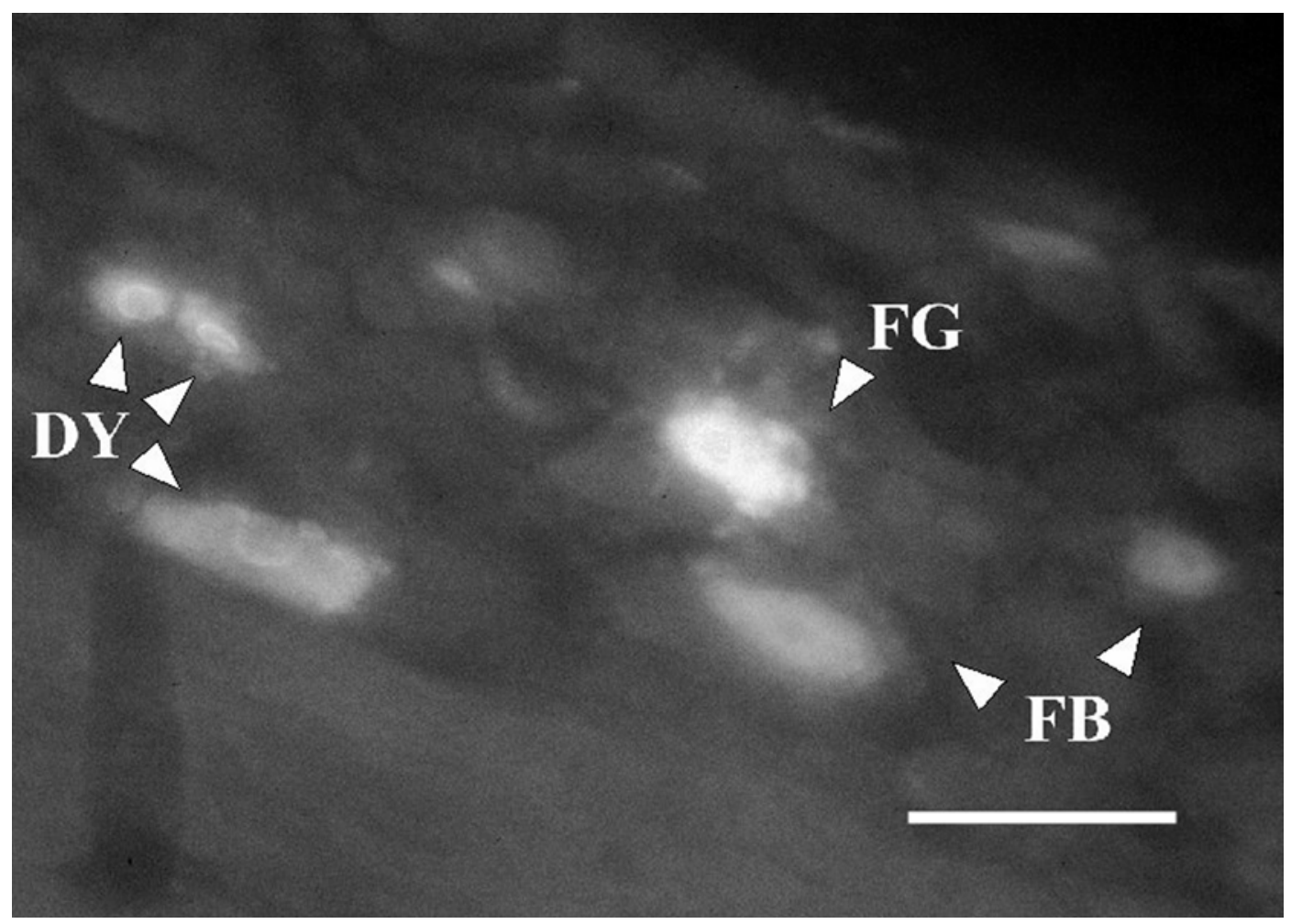


Figure 2. The mean numbers of labelled neuronal profiles per digit in each ganglion are represented without correction for split cells. Note the tendency of more medial digits to project to rostral ganglia while more lateral digits are progressively more represented in the caudal ganglia.

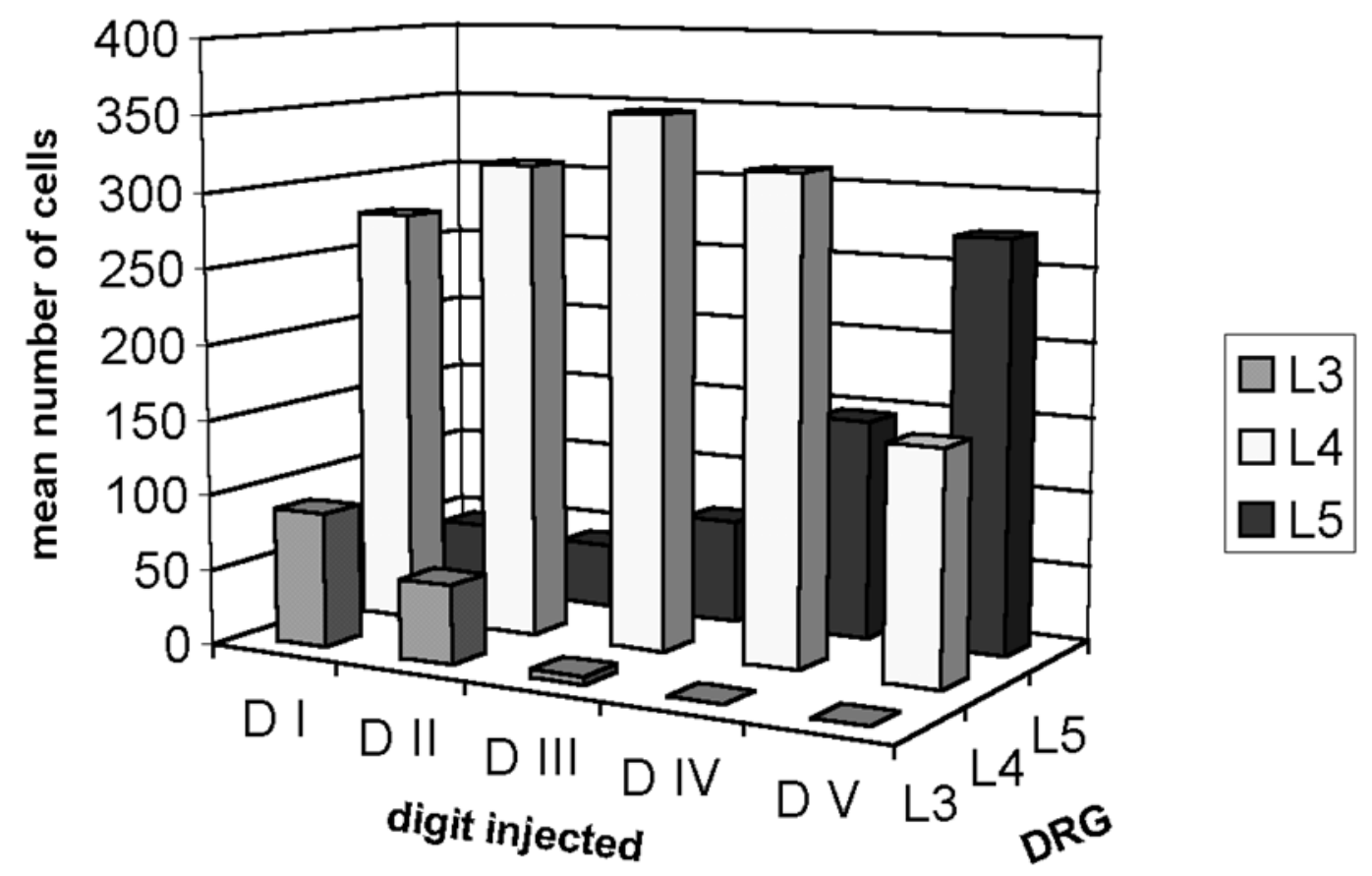


Figure 3. Three-dimensional reconstruction of the representations in DRGs L3 to L5 of digits I-V made from four representative cases (see Materials and Methods). The opacity of the "walls" of the reconstructed 3-D surfaces were reduced to $30 \%$ to allow visualisation of neuronal representations inside the DRG. Rostral (r), caudal (c), medial (m) and lateral (1). Scale bar: $500 \mu \mathrm{m}$.
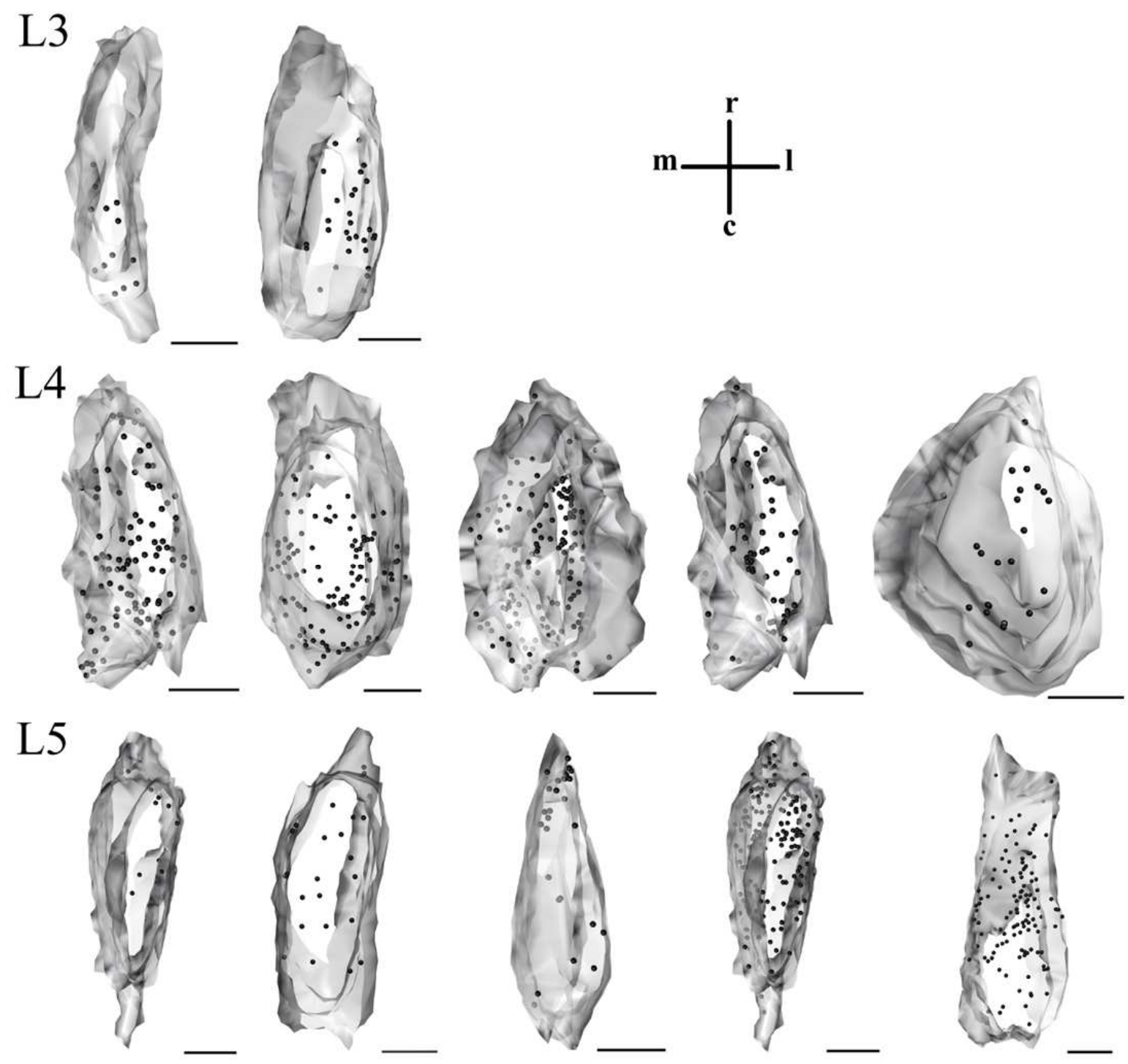

Digit I Digit II

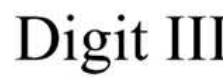

Digit IV

Digit V 
Figure 4. Models of DRGs at levels L3-L5 with representations of neuronal profiles found after injection in the different digits. Digit I, red; digit II, orange; digit III, yellow; digit IV, green; digit $\mathrm{V}$, blue.

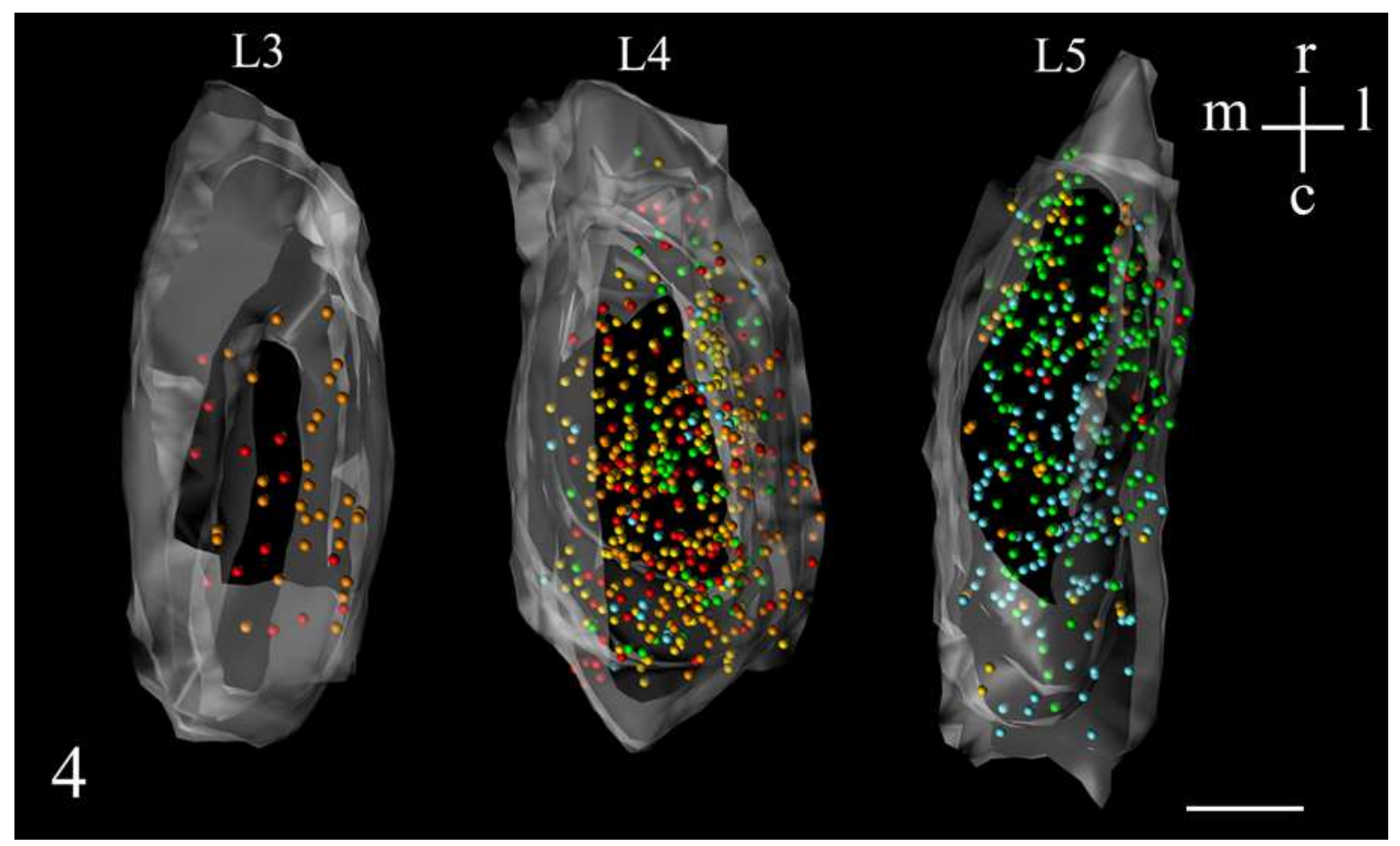


Figure 5. Plotted neuronal profiles projecting to digit IV (green) and digit V (blue) in L5 DRG of rats 136, 137, 138, 139, 140 and 162 . Note tendency of more rostral distribution of digit IV neurones in R136, R138, R139 and R162, whereas no such distribution is apparent in R137 and R140.

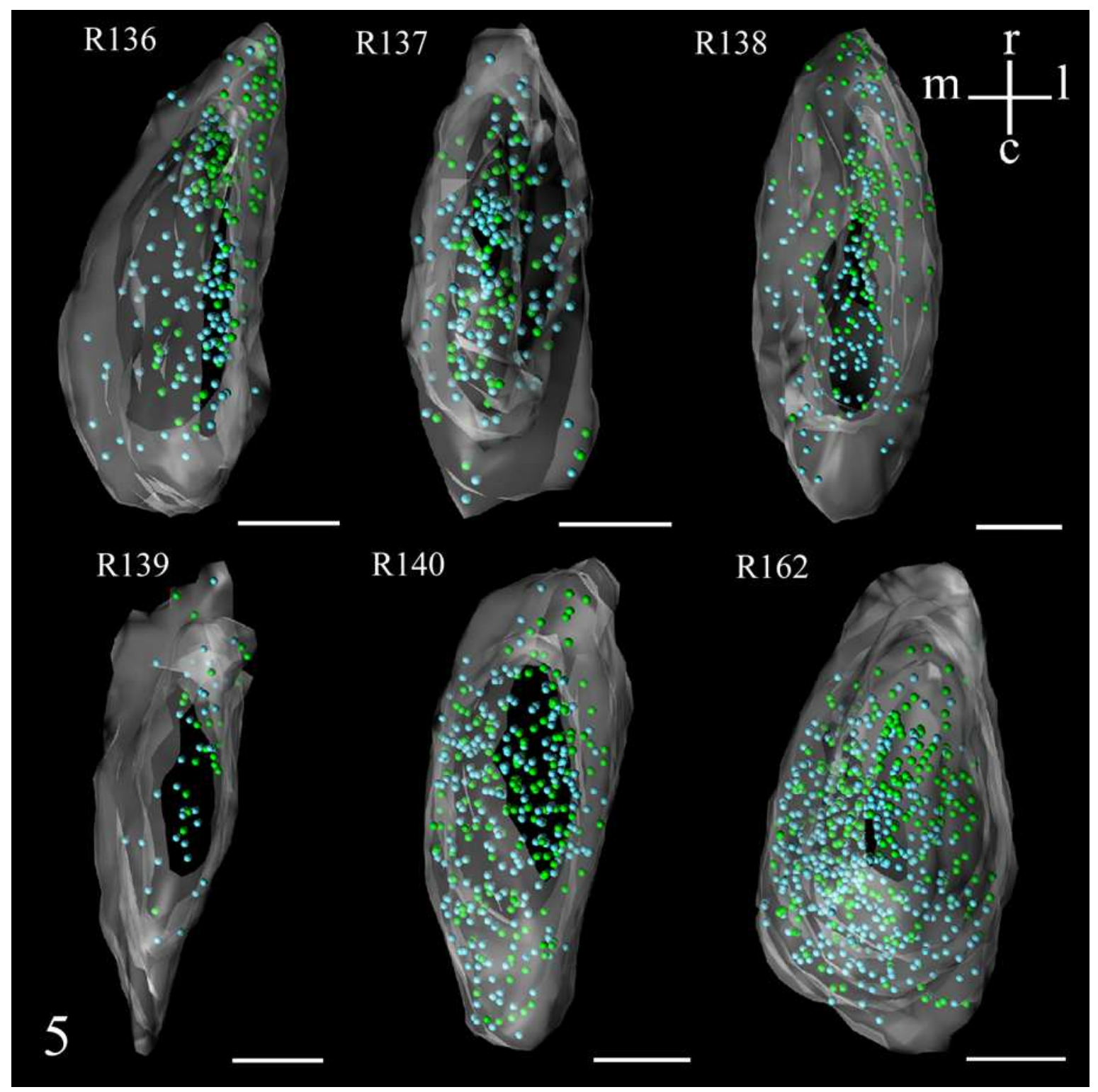

